\title{
Fire phenomenon in agate from Deer Creek (Arizona, USA)
}

\author{
Magdalena Dumańska-Słowik ${ }^{1}$, Lucyna Natkaniec- \\ Nowak $^{1}$, Adam Gaweł ${ }^{1}$, Joanna Kowalczyk-Szpyt ${ }^{1}$, \\ Stanislava Milovska ${ }^{2}$, Anna Łatkiewicz ${ }^{3}$ \\ ${ }^{1}$ Faculty of Geology, Geophysics and Environmental \\ Protection, AGH the University of Science and \\ Technology, 30 Mickiewicz Av, 30-059 Krakow, Poland \\ ${ }^{2}$ Earth Science Institute, Slovak Academy of Sciences, 1 \\ Ďumbierska str., 97411 Banská Bystrica, Slovakia \\ ${ }^{3}$ Institute of Geological Sciences, Jagiellonian University, \\ Krakow 30-387, 3a Gronostajowa str., Poland
}

Agate mineralization occurs in veins and cracks of volcanic rocks and their tuffs dated to Middle Eocene to Miocene in the Peach Springs Tuff and Apache Leap Tuff in the Galiuro Mts. in the USA (Horton et al., 2017). This mineralization is unique due to optical effects revealed on the surface of the polished gemstones. The best specimens show delicate red, blue, green and yellow flashes on the brown base. Under polarizng microscope the comb-like, colloform, moss and traces of jigsaw microtextures have been observed. The distinct predominance of primary growth microtextures over the jigsaw (mosaic), which resulted from recrystallization of primary silica phases, is characteristic for agates hosted in relatively young rocks. The structural and spectroscopic investigations revealed that agates are composed of poorly ordered chalcedony with moganite and opal C. These silica phases occur as bubble like and botryoidal forms. Under SEM observations these bubbles show layered structures. Only some of these layers contain randomly scattered tiny inclusions of iron and titanium oxides. The structure of these silica botryoidal forms, as well as the presence of magnetite, maghemite, anatase and rutile hosted in agates seem to be responsible for rainbow colors of the optical phenomenon (Natkaniec-Nowak et al. 2020).

\section{References:}

Natkaniec-Nowak L., Dumańska-Słowik M., Gaweł A., Łatkiewicz A. Kowalczyk-Szpyt J., Wolska A., Milovska S., Luptakova J., Ładoń K. (2020) Fire agate from Deer Creek deposit (Arizona, USA) - new insights into structure and mineralogy. Mineralogical Magazine,

https://doi.org/10.1180/mgm.2020.8

Horton J.D., San Juan C.A. and Stoeser D.B. (2017) The

State Geologic Map Compilation (SGMC) Geodatabase of the Conterminous United States. United States Geological Survey data series, 1052, $46 \mathrm{pp}$ 